\title{
An integrated social media communication view on content marketing by South African non-profit sectors
}

\begin{tabular}{|c|c|}
\hline \multicolumn{2}{|c|}{$\begin{array}{l}\text { Authors: } \\
\text { Christelle Swart }^{1} \text { (D) } \\
\text { Charmaine du Plessis }^{1} \\
\text { Elnerine Greeff }\end{array}$} \\
\hline \multicolumn{2}{|c|}{$\begin{array}{l}\text { Affiliations: } \\
{ }^{1} \text { Department of } \\
\text { Communication Science, } \\
\text { Faculty of Human Sciences, } \\
\text { University of South Africa, } \\
\text { Pretoria, South Africa }\end{array}$} \\
\hline \multicolumn{2}{|c|}{$\begin{array}{l}{ }^{2} \text { College of Graduate Studies, } \\
\text { University of South Africa, } \\
\text { Pretoria, South Africa }\end{array}$} \\
\hline \multicolumn{2}{|c|}{$\begin{array}{l}\text { Corresponding author: } \\
\text { Christelle Swart, } \\
\text { cswart@unisa.ac.za }\end{array}$} \\
\hline \multicolumn{2}{|c|}{$\begin{array}{l}\text { Dates: } \\
\text { Received: } 22 \text { Dec. } 2020 \\
\text { Accepted: } 07 \text { May } 2021 \\
\text { Published: } 16 \text { July } 2021\end{array}$} \\
\hline \multicolumn{2}{|c|}{$\begin{array}{l}\text { How to cite this article: } \\
\text { Swart, C., Du Plessis, C. \& } \\
\text { Greeff, E., 2021, 'An } \\
\text { integrated social media } \\
\text { communication view on } \\
\text { content marketing by } \\
\text { South African non-profit } \\
\text { sectors', South African } \\
\text { Journal of Information } \\
\text { Management 23(1), a1366. } \\
\text { https://doi.org/10.4102/ } \\
\text { sajim.v23i1.1366 }\end{array}$} \\
\hline \multicolumn{2}{|c|}{$\begin{array}{l}\text { Copyright: } \\
\text { (c) 2021. The Authors. } \\
\text { Licensee: AOSIS. This } \\
\text { is licensed under the } \\
\text { Creative Commons } \\
\text { Attribution License. }\end{array}$} \\
\hline \multicolumn{2}{|l|}{ Read online: } \\
\hline 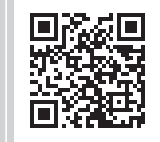 & $\begin{array}{l}\text { Scan this QR } \\
\text { code with your } \\
\text { smart phone or } \\
\text { mobile device } \\
\text { to read online. }\end{array}$ \\
\hline
\end{tabular}

Background: Organisations widely adopt social media to communicate with stakeholders, yet research into content marketing in the South African non-profit sector is sparse. It is concerned with consistently producing valuable and relevant content for social media. As it is generally associated with the field of marketing, limited research exists from a communication perspective. This perceived gap in taking a communication stance prompted this investigation into the ways in which these organisations attend to social media content aspects.

Objectives: The research objective was to acquire a broad understanding of content marketing on social media, unique to South African non-profit organisations. Key areas that were uncovered and statistically verified in an earlier quantitative study and how these are attended to in real life were explored.

Method: A qualitative approach was used to obtain in-depth insights into the use of content marketing. Semi-structured interviews were used as data collection method to explore non-profit sector's approaches to social media communication, and to determine whether their efforts could be regarded as being integrated.

Results: The findings yielded valuable insights into the ways that non-profit sectors in South Africa practise social media communication. The benefits of using social media for communication is acknowledged, yet vital aspects such as sourcing content, considering stakeholders' needs and demographics communication, using available planning tools and recognising employees as internal ambassadors are not considered.

Conclusion: The findings of this study highlight several key areas and topics that organisations should consider an integrated social media communication approach as alternative for content marketing in the non-profit sector.

Keywords: social media communication; content marketing; non-profit organisations; corporate brand; integrated social media communication.

\section{Introduction}

In the global communication landscape, social media networking sites have emerged as powerful platforms for non-profit organisations to communicate with stakeholders. The adoption of social media by non-profit organisations has been widely studied, yet there remains a paucity of evidence addressing social media communication (SMC) through an integrated lens within the context of content marketing. Also, despite the importance of brand content on social media to attract the target audience, to date, the integration of SMC for greater impact of brand content has received scant attention in the research literature, specifically for the South African non-profit sector. It is also still not known whether South African non-profit organisations consider an integrated perspective as important for their SMC when creating and sharing content.

In this regard, content marketing aims to consistently create and curate valuable and relevant information on a strategic level with an eye on changing or enhancing consumer behaviour and ultimately build beneficial consumer relationships (Ashley \& Tuten 2015; Content Marketing Institute 2019). Moreover, it is described as earning audience engagement by enhancing and advancing brand content that is shared on social media (Ho, Pang \& Cho 2020:146). When one considers these fundamental ambitions of content marketing, the potential benefit to non-profit organisations is evident. Sharing brand information is the key to non-profit organisations as the vehicle through which fundraising, corporate support and image and identity building take 
place (Hilpern 2013:38; cf. Bennett 2017:39). Social media content marketing is a new concept for many organisations, and as Odden (2012) puts it, if organisations do not participate in an integrated and strategic manner, they 'may find themselves joining in with too little too late in a never-ending game of catch up'.

As content management is generally associated with the field of marketing and is referred to as a marketing paradigm, limited research exists from a communication perspective. The lack of research with a distinctive communication stance largely prompted this investigation into how non-profit organisations' content is created and brand messages are conveyed on social media.

To address this gap in the literature, this article adopts an integrated social media communication (ISMC) standpoint to answer the following two research questions:

- How can SMC be integrated to practise content marketing coherently and strategically?

- How do non-profit organisations currently use content marketing?

This article is organised as follows: firstly, the theoretical foundation and aspects related to the focus of the research are presented by providing a synopsis of research into the elements of ISMC and key areas of SMC and content marketing. A communication perspective with the fundamental role of content is then outlined. Secondly, an integrated communication (IC) perspective to social media content marketing is conceptualised by identifying key areas and features from the literature discussed. Thirdly, the findings of the interviews are described and linked to these key areas and features. Then theoretical and practical implications of the study when practising ISMC within the context of content marketing are highlighted. Finally, concluding remarks are made with recommendations for further studies.

\section{Literature review}

This section addresses research objective 1, namely to investigate how SMC can be integrated by presenting the elements of ISMC and key areas of SMC and content marketing. This article centres around the notion that content marketing uses different social media platforms on which non-profit organisations could manage content to draw attention to and ultimately attain a favourable brand.

The view is that every message and action collectively qualifies as communication or touchpoint that positions the organisation in the minds of customers and as a result might attract stakeholders towards its mission and cause (Alizadeh et al. 2014). It can thus be anticipated that all touchpoints from and with the organisation are focused to ultimately draw or pull stakeholders to the brand and for this reason warrant consideration of the proposed approach. In context, this assumption is confirmed by the popular use of social media by organisations to communicate and by the fact that it has become embedded in people's daily lives (Nevius 2018; Salmons 2017). In relation to research by Du Plessis (2015) on elements of content marketing, the communication element features prominently but this article proposes an IC view as an organising approach that fortuitously encapsulates all the elements of Du Plessis in one way or another (see Table 1) (Ho et al. 2020:135). Similarities to the elements of Du Plessis (2015) and Ho et al. (2020) and the unique key areas underlined in this article are noticeable and corroborate an IC approach to a certain extent.

The definition by the Content Marketing Institute, as put forward by Pulizzi (2012), centres around content that needs to meet certain conditions and that is specifically aimed at attracting well-defined audiences with the aim to gain profit. Extant views primarily accentuate content marketing as a marketing paradigm (Ho et al. 2020:134) and do not consider the fact that communication is the concern of multiple management functions in non-profit organisations. Thus, in line with the focus at hand, a communication outlook on content marketing is deemed sensible and deserves investigation, as communication essentially strives to connect audiences to the corporate brand (cf. Dosemagen 2011).

\section{Fundamental role of content}

Social media content should be recognised as a strategic business asset that needs to be aligned with the organisation's goals, irrespective of the specific management function's outlook and use of communication (cf. Sun \& Asencio 2018). As Van Riel and Fombrun (2007) asserted, a system of communication consists of the types of strategic and tactical media that are used for communication and specifically centre around the content on social media in the current setting. Content is understood to be fundamental to social media and greatly allows participants to connect and interact socially to exchange information, drive conversations

TABLE 1: Key areas of an integrated communication approach to social media content marketing.

\begin{tabular}{|c|c|c|}
\hline Key areas & Level & $\begin{array}{l}\text { Content marketing } \\
\text { elements (Du Plessis } \\
\text { 2015; Ho et al. 2020) }\end{array}$ \\
\hline \multicolumn{3}{|c|}{ Key area 1: Fundamentals for integrating social media content } \\
\hline $\begin{array}{l}\text { - Social media presence and } \\
\text { communication strategy }\end{array}$ & Strategic level & Strategic element \\
\hline \multicolumn{3}{|c|}{$\begin{array}{l}\text { Key area 2: Brand contact points for social media content integration at various } \\
\text { levels }\end{array}$} \\
\hline $\begin{array}{l}\text { - Stakeholder integration } \\
\text { (conversation/dialogue) } \\
\text { - Social media content } \\
\text { (sourcing of content, } \\
\text { planning and scheduling } \\
\text { documents: Timing) } \\
\text { - Convergence of multiple } \\
\text { social media platforms }\end{array}$ & Technical level & $\begin{array}{l}\text { Formation element, } \\
\text { corollary element, } \\
\text { medium element, intrinsic } \\
\text { element, communication } \\
\text { element }\end{array}$ \\
\hline \multicolumn{3}{|c|}{ Key area 3: Sustain social media content integration } \\
\hline $\begin{array}{l}\text { - A social listening orientation } \\
\text { - Environmity } \\
\text { cross-functional and } \\
\text { - Management of synergy } \\
\text { and consistency of } \\
\text { communication endeavours } \\
\text { by an individual or team of } \\
\text { communicators } \\
\text { - Evaluation }\end{array}$ & Strategic level & $\begin{array}{l}\text { Strategic element, } \\
\text { corollary element, } \\
\text { intrinsic }\end{array}$ \\
\hline
\end{tabular}


and permit all participants to produce, change and share content freely (Ahmad, Musa \& Harun 2016; Jacobson, Gruzd \& Hernández-García 2020:2). Content is likewise central to views about content marketing, as evident in the view of Ho et al. (2020:146) and as other prominent scholars and practitioners concur (Albano-Davis 2019; Jacobson et al. 2020:3). For these reasons, content is recognised as the central point for all communication on social media.

\section{An integrated social media communication perspective to social media content marketing}

The primary contribution of this article is to provide insights into an integrated approach to SMC with specific consideration of the corporate brand and content marketing.

Areas with unique features that are of similar significance to social media content marketing as point of departure were explored, empirically tested and validated in advance by means of online surveys (Swart 2018). The findings confirmed strong linear associations between the areas and features and indicated that all of them were correctly grouped together (Swart 2018). Various insights into theoretical aspects, models and viewpoints were broadly conceptualised in three key areas: 'fundamentals for integrating social media brand communication, brand contact point for social media content integration and aspects to sustain social media content communication integration' (Swart 2018:346-354). These areas served as the basis for a qualitative investigation and were explored through semi-structured interviews to allow for a comprehensive understanding of how non-profit organisations in real life attend thereto.

Distinct strategic and tactical points to facilitate SMC in an integrated manner that centre on content are illustrated in Table 1 (Swart 2018:367). Table 1 also shows key areas and features that served as a guiding framework, including the similarities to Du Plessis's $(2015: 125,126)$ and Ho et al.'s (2020) content marketing elements.

The key areas discussed in Table 1 are succinctly explained in the following sections.

\section{Key area 1: Fundamentals for integrating social media content}

Unique aspects that could serve as the foundation of integrating social media brand communication were investigated. It was probed from the point of view that a social media presence and a communication strategy are nonnegotiable attributes and of strategic importance to organisations to communicate on social media (Swart 2018). Social media presence permits the organisation to have a human presence on various platforms (Pongpaew, Speece \& Tiangsoongnern 2017:265). An obvious benefit of having a presence on social media is the interaction with others that may promote engagement on these platforms, as revealed in a study by Pongpaew et al. (2017:275). Additional benefits of an online presence include the opportunity to increase awareness of the organisation through attracting attention, promoting favourable statements, allowing the organisation to monitor discussions and stating the organisation's point of view when necessary (Pongpaew et al. 2017:275). The significance of stakeholders' focus and their needs are emphasised. Related to this point is the need to recognise that an organisation's association with the brand is enabled based on the values of the organisation. A strategic directive to align and guide communication on social media with the objectives and goals of the organisation is recognised and underlines the importance of a social media or communication strategy (Sun \& Asencio 2018:2). Moreover, such SMC guidelines should be in place before the actual implementation of social media (Milde \& Yawson 2017:24).

\section{Key area 2: Brand contact points for social media content} integration at various levels

Brand contact points encapsulate various ways or points of contact through which the non-profit organisation connects and engages with its stakeholders on social media and through which integration can be realised (Swart 2018:370).

The three ways or features to promote the integration of social media are the integration of stakeholders, social media content and using social media combined with traditional media and the convergence of media. The assumption concerning stakeholder integration is the adoption of a listening orientation, through which audiences are involved in conversations or dialogue, which might be achieved by identifying ways of encouraging the positive sharing of information and soliciting contributions (Swart 2018:384). It is supposed that the participation of stakeholders in content creation and dissemination is solicited when the organisation actively listens to conversations and considers and responds to topics raised (Swart 2018:384).

Once organisations realise that content is the fundamental component of SMC they should be inspired to create and share content that is relevant and valuable to the organisation and their stakeholders (cf. Hollebeek \& MacKy 2019:32). It is all about employing social media content to create meaningful connections that will draw key individuals and groups to the content shared on social media and to eventually achieve a positive perception of the organisation (Swart 2018:56). This involves specific ways of keeping up with the needs of stakeholders and knowledge of the types of content they prefer.

The social media content feature focuses uniquely on the different types of content, as supported by views in literature. For purposes at hand the types of content are largely classified as 'created or owned, curated or repurposed' and 'co-created or earned/electronic word of mouth (eWOM)' (Basu 2018). This signifies that both the organisation and stakeholder should actively source content for SMC.

Media convergence consists of the use of multiple social media platforms and the combination of traditional and social media to distribute brand messages. This links to the fact that stakeholders can access multiple documents on 
social media at a given time (Rasmussen Pennington 2017). It can therefore be assumed that stakeholders will likewise access different social media and traditional platforms. The question is therefore whether these organisations use and combine different platforms.

\section{Key area 3: Sustain social media content integration}

This area comprises five features and is positioned on a strategic level and directed at achieving the preceding key areas set on strategic and tactical levels.

The first feature relates to the fact that amidst information overload in a social media environment, organisations need to accept that conversations about the brand will take place on social media because the way stakeholders communicate is inherently conversational (cf. Ahmad et al. 2016:331). Moreover, when information about a brand is shared, it could drive discussions on these platforms (Osei-Frimpong \& McLean 2018:18). For the purpose here, the concept 'conversation' refers to the connections on social media by stakeholders that may comprise different forms of action, for example, comments, posts, discussions, reviews, videos and the likes. Pomputius (2019:182) maintained that stakeholders expect of organisations to engage in and respond to these conversations. Considering the importance of this aspect, a listening and monitoring orientation is suggested.

A conversational focus may hold specific benefits and it can be anticipated that listening to conversations could reveal valuable information about the expectations, needs and topics of interest of stakeholders (Sun \& Asencio 2018:11; Swart 2018:226). This underlines the value of customer intelligence through which a holistic view can be developed. Listening could reveal the type of platforms where customers gather, the type of content they prefer and opportunities to influence discussions about the organisation (Pomputius 2019). Organisations should therefore locate their stakeholders and meet up with them where they congregate. This supports the notion of pulling that is typical of content marketing and SMC. Moreover, a listening approach could afford opportunities to participate in conversation that could equally prove to stakeholders that they are valuable to the organisation (Pomputius 2019). Organisations should realise that interactions on social media, such as conversations or sharing other types of content, will subsequently intensify discussions about the organisation, otherwise referred to as eWOM (Swart 2018:33,34). Electronic word of mouth refers to mentions and discussions by and between stakeholders that are not spread through traditional ways (Swart 2018:33,34).

Communities, as a second feature, are described as groups of people with the desire to connect, participate and collaborate with others (Nuccio 2020). Social media communities congregate around social media content and the interactions of others, such as replying, tweeting, reviews and ratings to name a few (Nadeem et al. 2020:1). The involvement and value of prominent stakeholders that exist in brand communities, namely, brand influencers, brand ambassadors and brand advocates, was explored (Swart 2018). It is expected that brand communities may serve as a foundation to widely share experiences and opinions about the brand and its cause and to establish connections with the brand.

The third feature of this area emphasises the need for an awareness of and consideration of an organisation's immediate environment. In this way they will be allowed to be adaptable and to keep up with technological developments (Swart 2018:227, 228). In addition, organisations need to acknowledge the importance of internal communication integration across the various management functions. This entails the connection and interaction between different departments and employees to share information and expertise (Sun \& Asencio 2018:3). Besides, the idea that the integration of employees could inspire them to act as brand ambassadors is thought to contribute to a sense of belonging internally.

The fourth feature is about the importance of the management of communication synergy and consistency by an individual or a team of communicators as evident in the literature. The role of an individual or team is specifically emphasised in contemporary South African models on IC. It is envisaged that this could promote the coordination and consistency of communication on social media, considering the multiple communication functions in the organisation that might adversely affect communication. Sun and Asencio (2018:4) stressed that a strategic approach to social media likely increases a non-profit's internal organisational capacity, including but not limited to connecting with others.

The evaluation of communication is the final feature and is regarded as non-negotiable and key to determine whether strategic objectives of organisation are being achieved (Keegan \& Rowley 2016:15), yet it is not given prominence in either historic or contemporary IC models. Considered together with the focus of this article, such measurement is vital to ascertain the progress towards an integrated approach to communication on social media. This feature highlights the need to uncover specific opportunities, threats, strengths and concerns together with comparisons to competitors and to determine whether stakeholders are satisfied that their voices are heard and considered (Swart 2018). The centre of interest is the value of evaluation as a key area to attain and sustain the integration of SMC.

\section{Research methods and design}

This study adopted an interpretive worldview that values the varied realities of individuals regarding an issue (Burton \& Bartlett 2009). This allowed for candid and authentic insights into the perspectives of individuals on SMC.

Pursuing objective 2, the aim was to obtain an in-depth understanding of the content marketing on social media unique to South African Non-profit organisations (NPOs), through a qualitative approach. In context NPOs is considered as those with a public purpose that do not benefit from financial gain or profit (Swart 2018). Semi-structured 
interviews were conducted with communication professionals of non-profit organisations to explore their approaches to SMC and to determine whether their efforts could be regarded as being integrated (Swart 2018). This method was deemed most suitable as information was obtained directly from professionals who are responsible for communication on social media and who could provide insights into the operationalisation thereof. It allowed for an in-depth investigation of certain key topics in a less structured and conversational way. An interview guide was developed and it served a threefold purpose: (1) to guide the conversation and ensure that it was confined to the set boundaries, (2) to maintain consistency in all questions and wording that were posed to all participants, and (3) to ensure that the topics were appropriate. The guide was pre-tested by a communication professional in the non-profit sector. Ethical clearance for the study was obtained prior to data collection.

The areas identified in Table 1 were translated into measurable items and specific topics were generated, which were discussed in the interviews (Table 2).

\section{Population and sample}

Specific challenges in terms of a trustworthy database or sample framework required explicit selection criteria to ensure that the selected organisations and individuals were able to provide expert information. The non-profit

TABLE 2: Key areas and topics explored during the semi-structured interviews.

\begin{tabular}{|c|c|c|}
\hline Key areas & $\begin{array}{l}\text { Strategic/technical } \\
\text { levels }\end{array}$ & Topics \\
\hline \multicolumn{3}{|c|}{ Key area 1: Fundamentals for integrating social media content } \\
\hline $\begin{array}{l}\text { Social media presence } \\
\text { and communication } \\
\text { strategy }\end{array}$ & Strategic level & $\begin{array}{l}\text { Challenges, basic } \\
\text { requirements, values }\end{array}$ \\
\hline \multicolumn{3}{|c|}{ Key area 2: Brand contact points for social media content integration at various levels } \\
\hline $\begin{array}{l}\text { - Stakeholder integration } \\
\text { (conversation/dialogue) } \\
\text { - Social media content } \\
\text { (sourcing of content, } \\
\text { planning and scheduling } \\
\text { documents: timing) } \\
\text { - Content convergence on } \\
\text { multiple social media } \\
\text { platforms }\end{array}$ & Technical level & $\begin{array}{l}\text { - Conversation/dialogue, } \\
\text { database } \\
\text { - Sourcing of content, } \\
\text { planning and scheduling: } \\
\text { timing } \\
\text { - Social media in conjunction } \\
\text { with traditional media, } \\
\text { interaction through } \\
\text { media convergence }\end{array}$ \\
\hline \multicolumn{3}{|c|}{ Key area 3: Sustain social media content integration } \\
\hline - Evaluation & Strategic level & $\begin{array}{l}\text { - Evaluation of social media } \\
\text { endeavours }\end{array}$ \\
\hline
\end{tabular}

organisation was expected: (1) to be registered on the Prodder and CharitySA directories, (2) to be a registered non-profit organisation in South Africa, (3) to be active on social media, (4) to be accessible to allow for the verification of the mentioned aspects, and (5) to have a dedicated communication professional who could manage social media. Purposive sampling was therefore applied to select the participants and data saturation was achieved after a total of 10 interviews.

\section{Data analysis}

With the necessary permission from participants, the interviews were recorded and transcribed by an impartial professional. Thematic deductive analysis was used to systematically analyse and code the data and interpret the themes by combining the approaches of Braun and Clarke (2006), Lapadat (2010) and Ryan and Bernard (2003). To ensure trustworthiness, triangulation was achieved by exploring prominent topics that were uncovered during the prior statistical research into ISMC. Unfortunately, time constraints did notallow the inclusion of all theoretical aspects.

The findings below are presented according to the preceding discussion of the IC approach to SMC.

\section{Findings}

The interviews set out to develop rapport with the participants and obtain details of their current position and experience in this sector. From the summary in Table 3, it is evident that all individuals held senior positions except for participants 6 and 10 who acted as consultant and volunteer, respectively. It is noteworthy that most individuals seemingly did not exclusively occupy communication positions but rather fulfilled more than one role, for example, as general manager, marketing and fundraising officer and marketing and communication manager. This suggests that these professionals are also responsible for other activities that are not primarily communication.

The participation in and duration of the interviews were determined by and restricted to the availability of the participants and ranged from 20 to $40 \mathrm{~min}$.

The discussions to follow attend to reporting the most noteworthy findings of the qualitative enquiry of the aspects

TABLE 3: Participants' profiles (Swart 2018).

\begin{tabular}{llll}
\hline Participants & Non-profit sector & Position in the organisation & Years at organisation \\
\hline Participant 1 & Social services & Media relations: external communication & 6 months \\
Participant 2 & Health & CEO and founder & 25 years \\
Participant 3 & Social services & General manager & 17 years \\
Participant 4 & Social services & Relationship manager & 10 years \\
Participant 5 & Health & Marketing and fundraising officer & 3 months \\
Participant 6 & Social services & Communication consultant & Female \\
Participant 7 & Health & National campaign manager & Female \\
Participant 8 & Education & Marketing and communication manager & 11 years \\
Participant 9 & Business & Marketing and campaign coordinator & 10 years \\
Participant 10 & Social services & Digital marketer/fundraiser & 1 year \\
\hline
\end{tabular}

CEO, chief executive officer. 
presented in Table 2 per the themes that became evident during the data analysis. In this way, research objective 2 about how content marketing is used by non-profits in South Africa is answered.

\section{Key area 1: Fundamentals for integrating social media content}

As indicated in Table 2, key area 1 broadly aimed at investigating the basics for brand communication on social media. The underlying notion is that a social media presence is a prerequisite for discussions amongst stakeholders about brands on these platforms (Osei-Frimpong \& McLean 2018:18). The focus was uniquely on the following three themes that were deductively identified in the literature: the challenges non-profit organisations face when communicating via social media, the basic requirements that should be in place when communicating with stakeholders and corporate brand values and their consideration thereof.

\section{Topic 1: Challenges for communicating on social media}

When asked about specific challenges facing individuals when communicating on social media, responses mainly evolved around content, the coordination thereof, social media messages and engagement on social media. It is evident that although content drives social media, these organisations do not follow a definite approach to aspects relating to social media content marketing,

\section{Theme 1: Content}

The participants displayed an awareness of appropriate and credible content that is apparently dependent on the type of organisation and key to content marketing, as previously stated. Participants said that '... it's about finding the most suitable content but to make sure it is relevant', 'you obviously need to have relevant and up-to-date content' and '... to be credible or to credibly tell you message'.

Some non-profit organisations who deal with sensitive issues and vulnerable audiences, such as human immunodeficiency virus/acquired immunodeficiency syndrome (HIV/AIDS) and children, raised the finding of such data as challenging. A participant commented that 'we deal with AIDS, HIV and AIDS [sic], right, so, it is not an easy subject, to talk about, or to post content about'.

The importance of a listening orientation was emphasised as follows: 'requires knowledge of your stakeholder, that requires knowledge of what uhm [sic] the public want to hear or want to find out from you'.

\section{Theme 2: Coordination of content}

Challenges pertaining to the coordination of content were mainly expressed by those who are employed in larger organisations that follow a decentralised approach to SMC. Comments included the following: 'you have the challenges of someone posting something that wasn't approved or perhaps spelling errors or that kind of thing' and 'for content purposes there were probably about six other people who contributed because we have six other branches'. The negative impact on the corporate brand was specifically identified: 'if they tweet something or say something on social media, people will link them to us'.

\section{Theme 3: Social media messages}

The interviews additionally uncovered uncertainties to determine whether messages reach the intended audiences and to create 'sort of unique selling points and differentiating oneself'. A participant mentioned that 'to get your message across is the main challenge'. The distribution of consistent messages was moreover emphasised and formulated, saying that 'we are quite inconsistent when we say something', and explained as referring to the 'regularity with which we post'. Moreover, this theme specifically relates to the timing of posts, tweets and others that in the view of Majid et al. (2019) are vital to reach stakeholders at an appropriate time. Not all organisations formally plan their content by, for example, using online scheduling tools, timelines or calendars.

\section{Theme 4: Issues around engagement}

Engagement on social media emerged as a fourth challenge. One participant outright admitted that 'it is difficult to engage' and to 'have engaging content' on social media. Considering scholarly standpoints in the literature, it is closely linked to conversations on social media and participation in such conversation by organisations. Engagement occurs when people connect on social media (when extensive conversations take place between the organisation and stakeholders and when individuals talk about the corporate brand and share its content (Ho et al. 2020; Osei-Frimpong \& McLean 2018:11).

\section{Topic 2: Basic requirements}

The basic requirements for social media brand communication explored the fundamentals for a social media presence and communication with stakeholders. The participants identified a variety of requirements, ranging from knowing the cause of the organisation, the need for experience and skills, a basic communication and social media background, providing more information and the importance of photos to access to technology. Interesting is the comment 'someone to manage it' that underlines the importance of an individual or team to achieve and maintain the integration of social media (Table 1).

Aspects related to the strategic intent and the aim to achieve a consistent corporate brand through IC were emphasised in the interviews. The point by a participant that stressed the need for 'emotional' and 'some motivational' content is fitting and in line with the notion that corporate branding aims to create emotional links to an organisation. Likewise, a participant elaborated on the importance of achieving brand consistency, by stating that the 'branding needs to be uniform'. The participants highlighted the need for strategic guidelines for communication on social media as follows: 'a strategy in terms of clear messages' and 'a clear strategy for 
social media'. The need to adopt a stakeholder perspective to allow organisations to understand 'who we're talking to, who we should be talking to, and who's out there in the space' was stressed.

The comment that employees are 'all ambassadors' draws consideration to the worth of employees as agents of the corporate brand and the point pertaining to cross-functional integration as a unique feature on strategic level (Table 1).

\section{Topic 3: Corporate brand values}

Corporate brand values as a fundamental element in the present context and for the existence of organisations was investigated.

Literature proposes that corporate values should be aligned with those of the stakeholders and the focus was predominantly on the ways in which non-profit organisations approach this (cf. Hollebeek \& MacKy 2019:32).

The participants largely admitted that their values undeniably define the organisation and are inherently linked to their respective causes: 'if people don't believe in your values or don't even know your values, then how do they support you?' and 'values are such an important part of this organisation in terms of who we hire, our internal stakeholders and of course our external stakeholders'. Only one participant believed that it is the responsibility of the organisation to be informed about their stakeholders' values and to align itself thereto: '.. as well as the mission clearly to the public and all the messages that go out on any platform, needs to be in alignment with those values'. It was concluded that organisations do not align their values with those of stakeholders per se but that associations with organisations are primarily made based on their corporate values. A participant affirmed this by saying that 'we stand by our own values'.

\section{Key area 2: Brand contact points of social media integration at various levels}

The views of the participants on the avenue of social media integration were established by exploring 'stakeholder integration (conversations and database), the way content is created and sourced' and 'the social media communication mix (using social media combined with traditional media)'.

\section{Topic 1: Stakeholder integration}

Considering the main use of social media by organisations currently, participants were asked to express their opinion on the main benefit or use thereof either to distribute information or to engage in two-way conversations with stakeholders (cf. Gearhart \& Maben 2019:1). The premise is that conversations by and with stakeholders are crucial in the question to achieve communication integration on social media. Specific reasons have been mentioned earlier (cf. Pomputius 2019). Although the benefit of information distribution was widely acknowledged during the interviews, there was recognition of the need for dialogue and the effect thereof on awareness of the corporate brand. A sequential relationship between information and dialogue was suggested: 'I would say information distribution creates you know a dialogue, in order to create awareness' and 'engaging in dialogue which in turn will result in the awareness that we are looking for'. Yet, most participants indicated that the purpose of social media was primarily to distribute information only.

The participants raised the difficulties they experience in terms of stakeholder segmentation because participation on social media is unhindered that prevents them from being informed of discussions and topics raised about the organisation.

\section{Topic 2: Creation and sourcing of content for social media}

As stressed earlier, content is fundamental to social media and the different types of content are created or owned, curated or repurposed and co-created or earned (eWOM) (cf. Mattke, Müller \& Maier 2019:802, 803).

These types denote the different opportunities for non-profit organisations to sensibly create and find suitable content, namely that content can be created by the organisation(s) and stakeholders and to gather content from a variety of sources (Mattke et al. 2019:802, 803). One participant indicated that content is sourced by a dedicated person 'looking for new content, following trends, discovering new things, being on the edge the whole time' and continue to motivate this tactic by saying that 'there is a lot more strength in our effort that we combine than our individual effort'.

It was apparent that most organisations do not intentionally source content and mainly use it to 'show people this is what we do with our money, with the money we have, this is the projects we do and this is how we do it'. In doing so many are of the view that it is imperative to acknowledge donors' contributions mainly by posting photos of 'donation drop-offs' or handovers and in this sense disregard possibilities to utilise and creatively source content. It is evident that they rely on visuals (photos) to communicate their messages and connect with the stakeholder, as already hinted on in the section on basic requirements and confirmed by a comment that 'we mainly rely on pictorial ... [sic]'. In this sense they do not consider the needs of stakeholders in terms of specific content and topics; 'literally when I stand up in the morning and I think of something' and 'we don't source anything ... a big lack from our side'.

Participants largely agreed on the importance of storytelling but raised sensitivity concerns that are obviously unique to the cause of every organisation. Only one organisation deliberately sources stories from its stakeholders by using emails to uncover topics.

\section{Topic 3: Social media brand communication mix}

The focus was twofold, that is, on the use of numerous social media platforms and the use of social media combined with traditional media (Basu 2018; cf. Fraccastoro, Gabrielsson \& Pullins 2020). Most participants engage in media convergence, 
which allows for the use of several platforms: 'when we have events that we do, we do live tweets' and 'so if we have a blog post I could just link that blog post to our twitter page', and 'We have a news release section, and then I would link from Facebook or Twitter, to that, to that news release'.

Reasons impeding the use of a communication mix pertain to time, budgetary constraints and the sensitive nature of their causes. Despite the value of combining social media and traditional media, organisations do not purposefully use them together.

\section{Key area 3: Sustain social media brand communication integration}

The evaluation of social media initiatives was purposely investigated in the interviews to obtain authentic insights into whether evaluation was a priority and how communication initiatives on social media are assessed.

Aspects such as online tracking and monitoring and the evaluation of the overall communication effort were discussed. Responses ranged from 'Not that good at it' to 'Mm. We just use the Facebook platform where, on your page, you can go to Insight' and 'No, it's way too academic'. The discussions revealed that non-profit organisations do not concentrate on staying informed of adverse statements or mentions of the corporate brand and mainly pay attention to the volume of posts and visits to their platforms that limit their ability to react or correct inaccurate statements or facts. In addition, they also do not use social media audits or a social media strategy that is a key requirement for ISMC (cf. Mulder 2015:18).

\section{Theoretical and practical implications of the study}

The theoretical implications for this study are twofold. Firstly, the study illustrates how SMC can be strengthened when an integrated approach is adopted to create and share content on social media platforms. Secondly, the findings extend our knowledge of how South African non-profit organisations currently use content marketing on social media to create awareness of their causes amongst their target audience. In doing so, the study's findings not only address the scarcity of studies on this topic but also stimulate further academic debate and studies.

Practically, the study findings point out several shortcomings, which non-profit organisations must address about their current SMC. Organisations should purposefully determine ways to successfully connect with their stakeholders by attending to the challenges they face and in doing so increase their engagement on social media. Only a few nonprofit organisations use the tools available for formal communication planning to attain consistent brand communication and overall uniformity. When sourcing content non-profit organisations generally should be mindful of stakeholders' needs and demographics and recognise employees as internal ambassadors. Also, the combination of traditional and SMC methods as put forward in this article should receive consideration and can contribute to achieving an integrated social media approach. Non-profit organisation should be attentive to the need for consistent brand communication and messages through which the organisation may be uniquely portrayed.

Furthermore, organisations should adopt a listening approach to be able to track conversations and mentions about the brand. Significant also is the increased competition with the corporate sector that uniquely challenges the operations of non-profit organisations and the management of content, such as creating, sourcing and coordinating thereof. It is evident that an IC approach to the practice of content marketing could become a heuristic to non-profit organisations when planning and executing their SMC.

\section{Conclusion}

Although the findings of this study cannot be generalised to the larger population and are only applicable to the sample, they nevertheless yield valuable insights into how nonprofit organisations in South Africa practise SMC within the context of content marketing. The contribution of this article mainly pertains to the identification of specific strategic and tactical points to achieve the integration of a comprehensive SMC on content marketing.

Future studies could refine the proposed key areas of ISMC and explore the possible relationships between them with a larger sample and using a quantitative approach. Opportunities also exist to investigate the application of ISMC in the for-profit sector.

\section{Acknowledgements}

The authors declare that they have no financial or personal relationship(s) that may have inappropriately influenced them when they wrote this paper.

\section{Competing interests}

The authors have declared that no competing interests exist.

\section{Authors' contributions}

C.S. conducted the overall doctoral study whilst registered as a student at the University of South Africa. C.d.P. was the supervisor and E.G. was the co-supervisor of the study and contributed to the writing of the article.

\section{Ethical considerations}

The researcher declared that the Policy for Research Ethics of UNISA was read and the study was carried out in strict accordance with the approved research proposal and the ethics policy of UNISA. Paragraph 5 of the Policy for Research Ethics in which integrity in research is detailed and UNISA's Policy for Copyright Infringement and Plagiarism were adhered to in conducting this research. 


\section{Funding information}

This research received no specific grant from any funding agency in the public, commercial or not-for-profit sectors.

\section{Data availability}

The data that support the findings of this study are available from the corresponding author (C.S.) upon reasonable request. The key areas of an integrated approach to social media brand communication (Table 1), developed by the researcher (C.S.), are the intellectual property of the said researcher.

\section{Disclaimer}

The views and opinions expressed in this article are those of the authors and do not necessarily reflect the official policy or position of any affiliated agency of the authors.

\section{References}

Ahmad, N.S., Musa, R. \& Harun, M.H.M., 2016, 'The impact of social media content marketing (SMCM) towards brand health', Procedia Economics and Finance 37 marketing (SMCM) towards brand health', Procedia Econo

Albano-Davis, M., 2019, 'Content that attracts clients', New Hampshire Business Review 40(16), 66-67. https://doi.org/10.1353/ner.2019.0050

Alizadeh, A., Moshabaki, A., Hoseini, S.H.K. \& Naiej, A.K., 2014, 'The comparison of product and corporate branding strategy: A conceptual framework', IOSR Journal of BusinessandManagement 16(1), 4-24. https://doi.org/10.9790/487X-16141424

Ashley, C. \& Tuten, T., 2015, 'Creative strategies in social media marketing: An exploratory study of branded social content and consumer engagement', Psychology \& Marketing 32(1), 15-27. https://doi.org/10.1002/mar.20761

Basu, A., 2018, Paid, owned \& earned media, viewed 07 June 2019, from https:// medium.com/swlh/paid-owned-earned-media-eae44c7275a1.

Bennett, R., 2017, 'Relevance of fundraising charitys' content-marketing objectives: Perceptions of donors, fundraisers, and their consultants', Journal of Nonprofit \& Public Sector Marketing 29(1), 39-63. https://doi.org/10.1080/10495142.2017.1 293584

Braun, V. \& Clarke, V., 2006, 'Using thematic analysis in psychology', Qualitative ResearchinPsychology3(2),77-101.https://doi.org/10.1191/1478088706qp063oa

Burton, D. \& Bartlett, S., 2009, Key issues for education researchers: Research paradigms and social perspectives, viewed 25 August 2020, from http://sk. sagepub.com/books/key-issues-for-education-researchers.

Content Marketing Institute, 2019, What is content marketing?: Useful content should be at the core of your marketing, viewed 02 June 2019, from https:// contentmarketinginstitute.com/what-is-content-marketing/.

Dosemagen, S., 2011, Role of the non-profit sector in leading innovation in public policy and social change, viewed 14 May 2019, from https://books.google.co.za/ books?id=9 fGbfXLqysC\&pg=PA441\&lpg=PA441\&dq=Salamon+1999\&source=b \&ots=kBBF_VOwc5\&sig=04voWKxunAUT3Te7Hnp14JXvTpU\&hl=en\&sa=X\&ved=0 ahUKEwiarLb1sdTWAhXjBcAKHVVgBXoQ6AEIVzAH\#v=onepage\&q=Salamon $\% 20$ 1999\&f=false.

Du Plessis, C., 2015, 'An exploratory analysis of essential elements of content marketing', in proceedings of the second European conference on social media, European conference of Social Media, pp. 122-129.

Fraccastoro, S., Gabrielsson, M. \& Pullins, M., 2020, International business review viewed 11 April 2021, from https://doi.org/10.1016/j.ibusrev.2020.101776.

Gearhart, C.C. \& Maben, S.K., 2019, 'Active and empathic listening in social media: What do stakeholders really expect', International Journal of Listening 2019, 1-22. https://doi.org/10.1080/10904018.2019.1602046
Hilpern, K., 2013, 'How to make content marketing work for you', The Marketer, pp. 38-41.

Ho, J., Pang, C. \& Choy, C., 2020, 'Content marketing capability building: A conceptual framework', Journal of Research in Interactive Marketing 14(1), 133-151. https:// doi.org/10.1108/JRIM-06-2018-0082

Hollebeek, L.D. \& Macky, K., 2019, 'Digital content marketing's role in fostering consumer engagement, trust, and value: Framework, fundamental propositions, and implications', Journal of Interactive Marketing 45, 27-41. https://doi. org/10.1016/j.intmar.2018.07.003

Jacobson, J., Gruzd, A. \& Hernández-García, A.A., 2020, 'Social media marketing: Who is watching the watchers?', Journal of Retailing and Consumer Services 53, 101774. https://doi.org/10.1016/j.jretconser.2019.03.001

Keegan, B.J. \& Rowley, J., 2016, 'Evaluation and decision making in social media marketing', Management Decision 55(1), 15-31. https://doi.org/10.1108/MD-102015-0450

Lapadat, J.C., 2010, 'Thematic analysis', in A.J. Mills, G. Durepos \& E. Wiebe (eds.), Encyclopedia of case study research, viewed 18 April 2016, from http://sk. sagepub.com/reference/casestudy/n342.xml.

Majid, S., Lopez, C., Megicks, P. \& Lim, A.M., 2019, 'Developing effective social media messages: Insights from an exploratory study of industry experts', Psychology and Marketing 36(6), 551-564. https://doi.org/10.1002/mar.21196

Mattke, J., Müller, L. \& Maier, C., 2019, 'Paid, owned and earned media: A qualitative comparative analysis revealing attributes influencing consumer's brand attitude in social media', in proceedings of the 52nd Hawaii International conference on system sciences. Grand Wailea, Hawaii, January 8-11, pp. 802-811.

Milde, K. \& Yawson, R.M., 2017, 'Strategies for social media use in nonprofits', Journal of Management Policy and Practice 18(1), 19-27.

Mulder, D., 2015, 'Introduction to integrated communication', in D. Mulder \& I. NiemannStruweg (eds.), Strategic integrated communication, pp. 1-24, Van Schaik, Pretoria.

Nadeem, W., Khani, A.H., Schultz, C.D., Adam, N.A., Attar, R.W. \& Hajli, N., 2020, 'How social presence drives commitment and loyalty with online brand communities? The role of social commerce trust', Journal of Retailing and Consumer Services 55 1-10. https://doi.org/10.1016/j.jretconser.2020.102136

Nevius, F., 2018, 'New media analysis', in M. Allen (ed.), The Sage encyclopedia of communication research methods, viewed 21 February 2019, from https://doi. org/10.4135/9781483381411.

Nuccio, L., 2020, Social communities, viewed 01 April 2021, from https://www. meltwater.com/en/blog/social-communities.

Odden, L., 2012, Optimize: How to attract and engage more customers by integrating SEO, social media, and content marketing, John Wiley \& Sons, Hoboken, NJ.

Osei-Frimpong, K. \& McLean, G., 2018, 'Examining online social brand engagement: A social presence theory perspective', Technological Forecasting \& Social Change 128, 10-12. https://doi.org/10.1016/j.techfore.2017.10.010

Pomputius, A., 2019, 'Can you hear me now? Social listening as a strategy for understanding user needs', Medical Reference Services Quarterly 38(2), 181-186. https://doi.org/10.1080/02763869.2019.1588042

Pongpaew, W., Speece, M. \& Tiansoongnern, L., 2017, 'Social presence and customer brand engagement on Facebook brand pages', Journal of Product \& Brand Management 26(3), 262-281. https://doi.org/10.1108/JPBM-08-2015-0956

Pulizzi, J., 2012, Six useful content marketing definitions, viewed 12 December 2018, from https://contentmarketinginstitute.com/2012/06/content-marketing-definition/.

Rasmussen Pennington, D., 2017, 'Coding of non-text data', in Sloan \& Quan-Haase (eds.), The Sage handbook of social media research methods, pp. 232-250, Sage, Los Angeles, CA.

Ryan, G.W. \& Bernard, H.R., 2003, 'Techniques to identify themes', Field Methods 15(1), 85-108. https://doi.org/10.1177/1525822X02239569

Salmons, J., 2017, 'Using social media in data collection: Designing studies with the qualitative e-research framework', in Sloan \& Quan-Haase (eds.), The Sage handbook of social media research methods, 161-176, Sage, Los Angeles, CA.

Sun, R. \& Asencio, H.D., 2018, 'Using social media to increase nonprofit organizational capacity', International Journal of Public Administration 42, 1-12.

Swart, C., 2018, 'A conceptual framework for social media brand communication in non-profit organisations in South Africa: An integrated communication perspective', Unpublished PhD thesis, University of South Africa (Unisa), Pretoria.

Van Riel, C.B.M. \& Fombrun, C.J., 2007, Essentials of corporate communication: Implementing practices for effective reputation management, Routledge, London. 